\title{
ENERGY OPTIMIZATION IN MODULAR BUILDINGS MADE FROM 3D PRINTING
}

\author{
S. Sepasgozar*, T. Huang*, C. Wang* and F. Tahmasebinia* \\ * University of New South Wales \\ e-mails: Sepas@unsw.edu.au, t.huang@unsw.edu.au, cynthia.wang@unsw.edu.au, \\ f.tahmasebinia@student.unsw.edu.au
}

\begin{abstract}
Off-site construction involves the process of designing, fabricating, transporting and installing building elements for rapid site assembly to a greater degree of finish than in other types of on-site construction methods. However, some pieces of the building depending on the geometry, materials and weight can be produced using $3 D$ printing on-site. Energy consumption can be modified based on the available resources on construction site such as labours, factories, and materials. This study focuses on energy optimisation based on simulating site available resources when $3 D$ printing technology is available. The paper compares three proposed different cases including balconies are entirely concrete, balcony Containers are replaced with soil and a shade factor was applied as well as case 2 with the added effect of evapotranspiration.
\end{abstract}

Keywords: 3D Printing, Sustainable Construction, Structures, Concrete, Energy Optimization.

\section{INTRODUCTION}

Sustainable architecture, green design, and sustainable development have become some of the most pertinent issues within the built environment. The building industry accounts for $35 \%$ of global final energy consumption and contributes to $17 \%$ of direct and $30-40 \%$ of indirect global C02 emissions [1]. Furthermore, the building industry consumes nearly 3 billion tonnes of raw materials; all of which approximately $40 \%$ becomes solid waste in the construction and demolition process [2]. These alarming statistics of the building sector calls for an investigation of an alternative construction approach that reduces the environmental impact of the construction process and the ongoing energy costs. Although studies have been completed on the sustainable benefits of the modular construction and 3D printing as independent fabrication methods, the combination of a modular building process and additive digital technology could potentially offer a more sustainable solution. Previous practices intended to introduce different modular technologies which are mainly off-site. However, the current modular technologies haven't been fully evaluated in terms of energy optimization. The energy optimization provides beneficial information to designers and contractors to select appropriate materials. In addition, the utilization of 3D printing provides flexibility to modular items both off site and on site to avoid transportation costs. The current study considers the potential energy consumption of concrete modular building using 3D printing technology. Besides, special attentions will be devoted to comprehensively evaluate the energy optimization in different simulated cases.

\section{MODULAR CONSTRUCTION PROCESSES}

The modular building process offers an alternative solution to increase efficiency, minimize waste and cost affordability for sustainable development. Modular buildings involve a process of planning, designing, fabricating, transporting and assembling building elements offsite for rapid on-site assemblage. This is completed in a monitored and controlled environment. This sector is expanding within the 
construction industry where its market share in the United States has doubled from $1.3 \%$ in 2012 to $2.72 \%$ in 2015 accounting for $\$ 3.1$ billion [3]. The growth of the sector can be attributed to the benefits of increased efficiency, streamlined process, and cost reduction to a typical traditional construction schedule. Across the spectrum of Modular products, modular, is the most complete in factory finish, up to $95 \%$ in some cases, shipped and assembled as $3 \mathrm{D}$ volumetric units that are service or structural units to be joined on-site. The modular industry consists of two distinct industry segments: re-locatable modular and permanent modular. Re-locatable modular, sometimes referred to as temporary modular, are structures which meet temporary spatial needs and can be leased in a short-term agreement or purchased outright. Job site trailers, temporary classrooms, communication pods, and showrooms are some examples. Although permanent modular construction (PMC) has been flourishing for a decade or more in Europe, it is an emerging market in North America. The modular industry is host to both manufacturers, manufacturer direct, and dealers. Manufacturers produce modules to service general contractors or modular dealers. Manufacturer directs may manufacture for general contractors and dealers, but also contract directly with owners to provide modular solutions, acting as a general contractor. Both manufacturers and manufacturer direct organizations may be specifically focused on a particular building type, residential or commercial for example, or focus on re-locatable and/or permanent construction. Increasingly, however, manufacturers are becoming knowledgeable and skilled across the array of building types, markets, and industry segments. Modular buildings, temporary and permanent, may be manufactured as structural units that make up the structure of the building once assembled on-site. Nonstructural modular such as factory fitted bathroom or service pods can be placed within a larger modular superstructure or in traditional construction on-site. Modules can be constructed from various materials including: wood framing, cold-formed steel framing, hot rolled steel, concrete, or a combination of material assemblages. Not all manufacturers will manufacture in many materials; rather manufacturers tend to focus on a particular type of construction to maximize factory efficiencies. The choice of material by stakeholders is usually contingent upon project demands, site forces, and project cost. Further, projects may have a hybrid of material solutions such as traditional site built structure, bathroom modules, or structural modules and a portion of the building that is traditionally site built due to programmatic demands such as large openings, spans or other that are difficult to pre-assemble in the factory.

\section{D PRINTING ADVANTAGES FOR MODULAR CONSTRUCTION}

The building industry has been moving towards automated processes to reduce the cost of production, provide safer labour practices, and decrease construction timelines [4]. A part of this automation is the development of additive technologies. Over the last 30 years, the development and growth of 3D printing (3DP) have made it a viable automated manufacturing method [5]. 3DP is an additive manufacturing (AM) method that joins layers upon layers of material to create three-dimensional objects. There are numerous variations of 3D printing technology that has been developed to suit different material inputs, scale, and performance. In this study, the focus will be on the additive manufacturing of concrete. Concrete is one of the most common materials used in the construction industry, with an annual global consumption of 23 trillion tones[6]. This consumption rate has significant impacts on the energy consumptions of buildings. To develop sustainable buildings, both embodied energy and operational energy must be considered. Embodied energy (EE) refers to the energy use and emissions produced during the manufacturing, transportation, installation, and demolition process. Operational energy (OE) refers to the energy consumption and emission of the building during use and ongoing maintenance. The calculation of embodied energy is complex, and no single method of calculation has been agreed upon[7] Therefore, this study will focus on the energy optimization that can be provided during the installation process for EE and consider OE through three case studies.

Traditional cast-in-situ concrete construction method has a significant amount of embodied energy with the raw material processing of sand, cement, binding agent to the transportation, and wet method installation process. The offsite option of pre-cast concrete provides energy savings as the panels are 
formed within a controlled environment. Furthermore, there are added benefits of an improved quality product, increase cost efficiency, minimize waste and reduce wastage. Although there are numerous benefits of pre-cast, it is not widely adopted in the industry. In the United States pre-cast concrete comprises $6 \%$ of the reinforced concrete sector, while in Europe, it comprises 18\% [8]. Also, the use of a pre-cast method may not always be suitable depending on the project parameters, contextual variations, and particularly for complex forms [9]. In addition, pre-casting requires a stringent designing and planning phase to ensure the cast is accurate. Any disruption or mishaps during the various phases can lead to extended lead times, increased costs, wastage and unnecessary energy consumption. 3D printing offers a more flexible process that can mitigate the variables, produce more complex forms and reduce energy consumption. Research in concrete 3DP has focused on the viability of 3D printing structural elements $[5,10,11]$, how to provide more form control and increase structural performance (Lim et al., 2011 ), and how to produce larger scale prints $[10,12]$. However, the amount of EE/energy optimization of concrete 3DP hasn't been modelled. Research in 3DP technologies within aerospace manufacturing, medical components and tooling shows a potential reduction of primary energy supply by $2.54-9.30 \mathrm{EJ}$ by 2025 [13]. 3DP has the potential to significantly reduce EE of concrete construction within the building industry and provide a flexible way to optimize OE. Furthermore, the utilization of 3DP for smaller parts in construction sites has not been explored. It is critical to consider the benefits of 3DP for both EE and OE optimization.

\section{ANALYSIS METHOD AND FINITE ELEMENT MODELS}

Three main cases are selected to be analysed using Finite Element modelling (FEM) methods using commercial code ABAQUS/Explicit. All cases are residential buildings, the same layout size of $200 \mathrm{sqm}$, with a single floor space ratio and located in NSW, Australia. The FEM is based on a typical floor of the structure. The energy consumption and costing is determined from each of following selected cases:

Case1. Balconies are entirely concrete.

Case2. Balcony Containers are replaced with soil and a shade factor was applied.

Case3. Same as case 2 with the added effect of evapotranspiration.

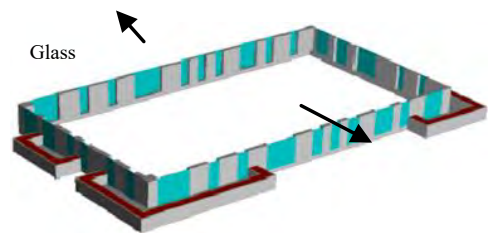

Figure 1. ABAQUS Model of Typical Floor (including concrete, glass \& soil elements)

The main structural component is $32 \mathrm{MPa}$ concrete. Glass windows follow a similar pattern to the actual design used in reality. Each balcony has a container that was filled with soil. Figure 1 shows the ABAQUS/Explicit model of the floor.

The structure was divided into 3 groups: 'Mould', 'Inside' and 'Outside'. The purpose of the 'Mould' was to stop the faces on the top and bottom of the wall from being 'free faces'. If they become free faces, boundary conditions will automatically be applied which is not desirable. The 'Mould' was removed in the analysis to keep the boundaries isolated. The walls were subdivided into two bricks along their width. The bricks with free faces on the inside were added to the group 'Inside'. The remaining bricks which have free faces on the outside surface were added to the group 'Outside'. By grouping the structure in this way, loads could then be applied more easily to the relevant surface. The alternative was to select faces by region for every individual input. This would be undesirable as there would be too many different inputs to create. 


\section{THERMAL BOUNDARY CONDITIONS}

The thermal boundary conditions are dependent on three major aspects; case, position and time. A transit analysis was considered so that the effect of the time history broadly will be studied.

\section{Convection}

ABAQUS uses the following formula to determine convection:

$$
q_{\text {conv }}=h_{c}\left(T-T_{\text {ref }}\right)
$$

$q_{\text {conv }}=$ Convection in or out of the surface of a body $\left(\mathrm{W} / \mathrm{m}^{2}\right)$

$h_{c}=$ Convective heat transfer coefficient $\left(\mathrm{W} / \mathrm{m}^{2} /{ }^{\circ} \mathrm{C}\right)$

$T=$ Temperature at the surface of the body $\left({ }^{\circ} \mathrm{C}\right)$

$T_{\text {ref }}=$ Ambient temperature $\left({ }^{\circ} \mathrm{C}\right)$

Convection was applied to all surfaces next to air (free surfaces). In all of the simulated surfaces, a convection coefficient of $11 \mathrm{~W} / \mathrm{m} 2 /{ }^{\circ} \mathrm{C}$ was applied. This value corresponds to still air. For this analysis we do not take wind actions into account. On the inside wall we assumed an ambient temperature of $22^{\circ} \mathrm{C}$ to mimic the constant temperature of an air conditioned floor. On the outside wall we assumed a varying ambient temperature simulating the effects of air temperature outside the building over a 10 day period in Milan. The air temperature ranged from $17^{\circ} \mathrm{C}$ to $30^{\circ} \mathrm{C}$ (mean $23.5^{\circ} \mathrm{C}$ ). The outside ambient temperature was input as a Factor vs Time Table in ABAQUS. Equation 2 is the outside ambient temperature varying over time. Note that $\mathrm{t}=0$ at $6 \mathrm{am}$.

$$
T_{\text {ref }}=23.5+6.5 \sin \left(\frac{2 \pi}{24} t\right)
$$

Convection on the inside wall is: -

$$
q_{\text {conv }}(t)=h_{c}(T(t)-22)
$$

Convection on the outside wall is: -

$$
q_{\text {conv }}(t)=h_{c}\left(T(t)-23.5+6.5 \sin \left(\frac{2 \pi}{24} t\right)\right)
$$

\section{Radiation}

ABAQUS uses the following formula to determine radiation: -

$$
q_{\text {rad }}=\sigma h_{r}\left(T^{4}-T_{r e f}^{4}\right)
$$

\footnotetext{
$q_{\text {rad }}=$ Radiation in or out of the surface of a body $\left(W / \mathrm{m}^{2}\right)$

$h_{r}=$ Radiation heat transfer coefficient

$T=$ Temperature at the surface of the body $\left({ }^{\circ} \mathrm{C}\right)$

$T_{\text {ref }}=$ Ambient temperature $\left({ }^{\circ} \mathrm{C}\right)$

$\sigma=$ Stefan Boltzman Constant $5.67 * 10^{-8}\left(\mathrm{~W} / \mathrm{m}^{2} / \mathrm{K}^{4}\right)$
}

Radiation was applied to all free boundary surfaces. For all surfaces experiencing radiation, a radiation heat transfer coefficient was applied: -

$$
h_{r}=F \varepsilon
$$

$F=$ Form factor

$\varepsilon=$ Emissivity

Since all surfaces in our model were relatively flat they could radiate heat more efficiently. The form factor, $\mathrm{F}$, for all surfaces was therefore 1 . In the model we gave glass the same value as concrete. If the 
emissivity of glass was taken into account, the grouping system would become more complex. Ambient temperatures were applied to the inside and outside surfaces in the same manner as convection.

Radiation on the inside wall is: -

$$
q_{\text {rad }}(t)=\sigma \varepsilon\left(T(t)^{4}-22^{4}\right)
$$

Radiation on the outside wall is: -

$$
q_{\text {rad }}(t)=\sigma \varepsilon\left(T(t)^{4}-\left(23.5+6.5 \sin \left(\frac{2 \pi}{24} t\right)\right)^{4}\right)
$$

\section{Evapotranspiration}

Evapotranspiration is the combined effect of evaporation and transpiration. It is a form of Latent heat as it is a phase change from liquid to gas. The water molecules need energy in order for this phase change to occur. In our model, energy is absorbed from either the surface of a leaf or the surface of soil. For this reason we regard evapotranspiration as a surface heat flux in the heat equation. Evapotranspiration is sometimes modelled as a volumetric heat flux or source flow. We did not model evapotranspiration as a volumetric heat flux as the surfaces have no electrical or chemical means of generating their own internal energy. There are some chemical reactions, unrelated to evapotranspiration that happen within the leaf which include photosynthesis and respiration. These reactions can generate internal heat, although for workability they have not been considered in the model.

Recent studies show that the value of heat flux for evapotranspiration can be up to $58 \%$ or $60 \%$ of absorption. Evapotranspiration was taken into account by adjusting the absorption flux since only one flux can be applied to one face. The shade factor (s) from case 2 also needed to be taken into account. For case 3 the factor value is reset to 1 and shade is applied to the values in the table. At the same time a factor (e) for evapotranspiration was accounted for.

$$
e=1-0.58=0.42
$$

Absorption in time including shade and evapotranspiration for soil as shown in equation 17 and equation 18 are input into Factor vs Time tables.

For case 3: -

$$
\begin{gathered}
q_{a b s}(t)=\text { e.s. } \alpha \cdot q_{\max } \sin \left(\frac{2 \pi}{24} t\right) \quad \text { for } q_{a b s}(t)>0 \\
q_{a b s}(t)=0 \quad \text { for } q_{a b s}(t) \leq 0
\end{gathered}
$$

\section{NUMERICAL ANALYSIS}

\section{Numerical Method}

For the numerical analysis, solid elements were used. There is an advantage of using solid element, in that heat properties can be determined through the thickness of the element. This is important for determining heat flux through the wall of our structure and ultimately determining the cooling cost. There is also a problem for lining up faces in the columns. Figure 2 shows how the result of faces not lining up in the columns can lead to unusual flux directions.

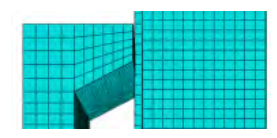

Figure 2. Misalignment of faces 


\section{Governing Equations}

In forming the governing equations of the problem, we need to establish kinematic, constitutive and balance equations. The kinematic equation is the temperature gradient. The temperature gradient is proportional to the conductivity.

Where the operator $\nabla$ is the vector,

$$
\nabla T \propto q
$$

$$
\nabla=\left[\begin{array}{l}
\frac{\partial T}{\partial x} \\
\frac{\partial T}{\partial y} \\
\frac{\partial T}{\partial z}
\end{array}\right]
$$

The constitutive equation introduces the conductivity $(\mathrm{k})$ of the material. As heat conducts out of the element, the positive change in heat flux through the path of heat flow will contribute to a negative change in temperature through the path of heat flow.

$$
q=-k \nabla T
$$

The principal of the balance equation is that the internal energy must equal the applied energy. To make the equation simpler we can write the balance equation in terms of power per unit volume.

$$
\frac{\partial U}{\partial t}=-\nabla^{T} q+Q
$$

Where $\mathrm{U}$ is the energy per unit volume and $\mathrm{Q}$ is the heat power generated per unit volume.

U can also be expressed as: -

$$
U=\frac{\text { Energy }}{V}=\frac{M C T}{V}=\rho C T
$$

Where $\mathrm{M}$ is the mass of the element, $\mathrm{C}$ is the heat capacity of the element, $\mathrm{V}$ is the volume of the element and $\rho$ is the density of the element. By substituting Equation 21 and Equation 23 into Equation 22: -

$$
\begin{gathered}
\rho C \frac{\partial T}{\partial t}=-\nabla^{T}(-k \nabla T)+Q \\
\rho C \frac{\partial T}{\partial t}=k \nabla^{T} \nabla T+Q
\end{gathered}
$$

It was suggested that based on the transient heat equation ( ABAQUS users' manual,2012), the governing equation for the problem: -

$$
\rho C \frac{\partial T}{\partial t}=k \frac{\partial T}{\partial x}+k \frac{\partial T}{\partial y}+k \frac{\partial T}{\partial z}+Q
$$

\section{Implementation of Boundary Conditions to the Governing Equations}

Previously the governing equation only looked at elements within the body. To implement boundary conditions, we need to adjust the governing equation to account for surface flux inputs.

$$
\rho C \frac{\partial T}{\partial t}=k \frac{\partial T}{\partial x}+k \frac{\partial T}{\partial y}+k \frac{\partial T}{\partial z}+Q+\nabla^{T}(q \cdot \hat{n})
$$

Where $\hat{n}$ is the unit vector normal to the surface and $q \cdot \hat{n}$ is represented by Equation 28 ,

$$
q \cdot \hat{n}=q_{c o n v}+q_{\text {rad }}+q_{a b s}+q_{e t}
$$

Where $q_{e t}$ is the surface flux due to evapotranspiration. The methods for calculating each surface flux is given in the boundary conditions section.

There is also the initial condition: -

$$
T(t=0)=26^{\circ} \mathrm{C}
$$


No source heat (Q) was used in the model. The model was solved for a 10 day time period in Milan. One hour time steps were implemented with a total of 240 time steps.

\section{The Obtained Results}

The following results were obtained from the transient heat solver. The temperature contours are displayed for all three cases at mid-day of the first day $(\mathrm{t}=6)$. As the suggested analysis is a transient thermal analysis, thus, the time can play a significant role in the suggested analysis. Figures 3 to 5 can present the temperature changes by respecting to the simulated time in different developed FE models. We used the transient heat equation to derive a formula for cost (see Appendix 1 for derivation). The cost $\mathrm{C}$ to cool the building over the total time period is determined using equation 23 .

$$
C=R A \Delta t \sum_{t=1}^{m}\left(\sum_{i=1}^{n}-q_{f l u x}\right)
$$

Where: -

$R=$ rate of electricity

$A=$ area of each brick

$\Delta t=$ time between each time-steps

$t=t^{\text {th }}$ time step

$m=$ number of time steps

$i=i^{\text {th }}$ brick

$n=$ number of bricks on inside wall

$\mathrm{q}_{\mathrm{flux}, \mathrm{t}}=$ heat flow from the $i^{\text {th }}$ brick through the inside surface of the building at time step

$t$ where heat flux out of the building is positive

$\mathrm{q}_{\text {flux }}$ was obtained by observing the listings provided by ABAQUS of each brick flux on the inside wall. The energy and cost for each case is shown in Table 2. The total energy is the overall input energy in the system. Furthermore, the total cost is calculated based on the amount of the consumed energy/dissipated energy through the momentum energy exchanges.

Table 2. Energy/Cost comparison to cool one floor over a 10 day period

\begin{tabular}{|c|c|c|}
\hline Case & Total Energy $(\mathrm{kWh})$ & Total Cost (AU\$ 2015) \\
\hline 1 & 6752 & 1260.76 \\
2 & 4741 & 841.45 \\
3 & 3718 & 657.87 \\
\hline
\end{tabular}

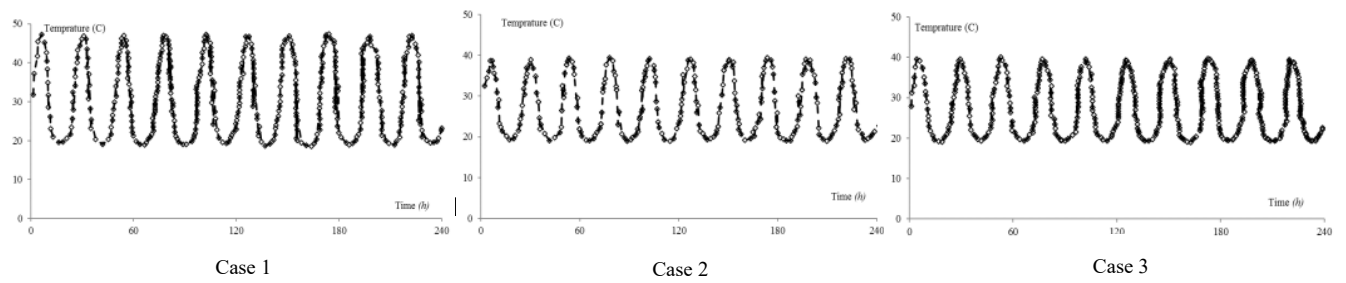

Figure 3. Temperature vs Iime for all cases

\section{CONCLUSIONS}

The aim of this study is to evaluate the energy optimization/consumption in different simulated cases using commercial packages ABAQUS/Explicit. A finite element method using ABAQUS was utilized to simulate a single floor systems with three different cases using solid element. The wall materials were selected both concrete and glass. The concrete balconies have containers that may be filled with soil, 
depending on the case. Boundary conditions on the outer surfaces of the model included absorption, convection, radiation and evapotranspiration. Each condition was modelled as a surface heat flux. Isolated boundaries occur at the ceiling and floor of the model. Three cases were developed in order to investigate the different simulated facades to evaluate the effect of the natural ventilation as well as the energy options. This suggests that the cost reduction caused by adding the façade is mostly due to the effects of shading rather than evapotranspiration. The reason for this is that evapotranspiration causes a local cooling in the balcony that is not transferred through to the inside of the building. The analysis shows that flexible scale of 3DP allows for small and large components to be completed with no disruption to the manufacturing process. This saves energy inputs in the manufacturing process but also allows for additional components to be added or removed to reduce operational energy. As per case studies 1 and 2, the added component of a shade factor reduced cost and service energy by $34.8 \%$. Case 3 shows a $35.1 \%$ cost reduction from case 1 . This phenomenon would be taken placed due to the effect of the more energy absorption in the case 1 . The ability to print smaller components with minimal manufacture time also reduces the total operational energy. 3DP provide more control via an automated digital process from digital file (CAD) to manufacturing. This digitalization is beneficial for designers and producers to develop more complex shapes, monitor the manufacturing time, manufacturing energy input and overall cost. This in turn also minimize unnecessary waste that may occur during the installation phase. 3DP can operate on site or off site depending on the project requirements. This minimalizes the transportation requirements, and where necessary for Modular construction, the controlled environment optimizes energy input.

\section{REFERENCES}

[1] IEA, "World Energy Outlook". 2013.

[2] UNEP, "Towards a Green Economy: Pathways to Sustainable Development and Poverty Eradication". 2011.

[3] MBI, "PMC \& RB Annual Statistical Report". 2016.

[4] Lim S, et al., "Developments in construction-scale additive manufacturing processes". Automation in Construction, 21: p. 262-268,2012.

[5] Lim S, et al. "Development of a viable concrete printing process". in Proceedings of the 28th International Symposium on Automation and Robotics in Construction, ISARC 2011. 2011.

[6] Miller D, J-H Doh, and M Mulvey, "Concrete slab comparison and embodied energy optimisation for alternate design and construction techniques". Construction and Building Materials, 80: p. 329-338,2015.

[7] Cabeza LF, et al., "Affordable construction towards sustainable buildings: review on embodied energy in building materials". Current Opinion in Environmental Sustainability, 5(2): p. 229236,2013 .

[8] Sacks R, CM Eastman, and G Lee, "Process model perspectives on management and engineering procedures in the precast/prestressed concrete industry". Journal of Construction Engineering and Management, 130(2): p. 206-215,2004.

[9] Chen Y, GE Okudan, and DR Riley, "Sustainable performance criteria for construction method selection in concrete buildings". Automation in Construction, 19(2): p. 235-244,2010.

[10] Cesaretti G, et al., "Building components for an outpost on the Lunar soil by means of a novel 3D printing technology". Acta Astronautica, 93: p. 430-450,2014.

[11] Khoshnevis B, et al., "Mega-scale fabrication by Contour Crafting". International Journal of Industrial and Systems Engineering, 1(3): p. 301-320,2006.

[12] Gosselin C, et al., "Large-scale 3D printing of ultra-high performance concrete - a new processing route for architects and builders". Materials \& Design, 100: p. 102-109,2016.

[13] Gebler M, AJM Schoot Uiterkamp, and C Visser, "A global sustainability perspective on 3D printing technologies". Energy Policy, 74: p. 158-167,2014. 